\title{
Antibacterial efficacy of Jackfruit rag extract against clinically important pathogens and validation of its antimicrobial activity in Shigella dysenteriae infected Drosophila melanogaster infection model
}

Dhwani NV 1 , Gayathri Raju1, Sumi E Mathew1, Gaurav Baranwal1, Shivakumar B Shivaram1, Neeraj Katiyarı, Nilkamal Pramanik2, Siddharth Jhunjhunwala2, Shilpashree, H.B.3, Dinesh A. Nagegowda3, Ritesh Kumar4, Ajit K. Shasany4, Raja Biswas*, 1, Sahadev A Shankarappa*, 1

1 Center for Nanosciences \& Molecular Medicine, Amrita Institute of Medical Sciences \& Research Center, Amrita University, Ponekkara P.O., Kochi 682041, India

${ }_{2}$ Centre for BioSystems Science and Engineering, Indian Institute of Science, Bengaluru 560012, India

3 Molecular Plant Biology and Biotechnology Lab, CSIR-Central Institute of Medicinal and Aromatic Plants, Research Centre, Bengaluru - 560065, India.

4 Biotechnology Division, CSIR-Central Institute of Medicinal and Aromatic Plants, P.O. CIMAP, Lucknow - 226015, India.

* Co-corresponding author

\section{Corresponding author address:}

Sahadev A Shankarappa, MBBS, MPH, Ph.D.

Assistant Professor

Center for Nanosciences and Molecular Medicine

Amrita Institute of Medical Sciences and Research Center

Amrita University

Ponekkara P.O., Kochi 682041

India

Phone: 91-4842-801234 (Ext. 8705)

Fax: 91-4842-802030

Email: sahadevs@aims.amrita.edu / sahadevs@icloud.com

\section{Abbreviations:}

CFU, colony forming units; DPPH, diphenyl-1-picrylhydrazyl hydrate; FBS, fetal bovine serum; FTIR, Fourier-transform infrared spectroscopy; JFRE, jackfruit rag extract; MBC, minimum bactericidal concentration; MIC, minimum inhibitory concentration; MTT, 3-(4,5, dimethylthiazol2-yl)-2, 5-diphenyltetrazolium bromide; SEM, scanning electron microscope, GC-MS, Gas chromatography mass spectrometry. 


\section{Abstract}

44 The aim of this study was to determine the antibacterial property of extract derived from a part

45 of the Jackfruit called 'rag', that is generally considered as fruit waste. Morpho-physical characterization of the Jackfruit rag extract (JFRE) was performed using gas-chromatography,

47 where peaks indicative of furfural; pentanoic acid; and hexadecanoic acid were observed. In

48 vitro biocompatibility of JFRE was performed using the MTT assay, which showed comparable

49 cellular viability between extract-treated and untreated mouse fibroblast cells. Agar well disc

50 diffusion assay exhibited JFRE induced zones of inhibition for a wide variety of laboratory and

51 clinical strains of gram-positive and gram-negative bacteria. Analysis of electron microscope

52 images of bacterial cells suggests that JFRE induces cell death by disintegration of the bacterial

53 cell wall and precipitating intracytoplasmic clumping. The antibacterial activity of the JFREs

54 was further validated in vivo using Shigella dysenteriae infected fly model, where JFRE pre-

55 fed flies infected with $S$. dysenteriae had significantly reduced mortality compared to controls.

56 JFRE demonstrates broad antibacterial property, both in vitro and in vivo, possibly by its

57 activity on bacterial cell wall. This study highlights the importance of exploring alternative

58 sources of antibacterial compounds, especially from plant-derived waste, that could provide

59 economical and effective solutions to current challenges in antimicrobial therapy.

60

61 Keywords: gut bacteria, antimicrobial, ingestion, antibiotic alternative, plant extract 


\section{Introduction}

63 Antimicrobial agents including antiseptics and antibiotics are extensively used for infection

64 control in community and nosocomial settings. Antiseptics such as chlorhexidine digluconate,

65 triclosan and povidone-iodine are used as surface disinfectants in hand hygiene and disinfection

66 of surgical and catheter insertion sites. In addition to human use, antibiotics such as ampicillin,

67 amoxicillin, imipenem, and many others, are widely used to treat a variety of bacterial

68 infections in animals, thus favoring their use in animal and poultry farming. Unfortunately,

69 enhanced use of antimicrobial agents leads to the development of resistant microbes, such as

70 chlorhexidine and colistin resistant Klebsiella pneumonia, methicillin and linezolid resistant

71 Staphylococcus aureus, and vancomycin-resistant enterococci. Importantly, some of the

72 antiseptics and antibiotics have also been reported to precipitate adverse systemic effects in

73 patients1. Povidone-iodine and triclosan has been shown to disrupt thyroid hormone

74 homeostasis 2, while colistin and vancomycin have been associated with renal toxicity 3,4. Thus,

75 it is imperative that new and safe antimicrobial agents are explored from alternative sources.

76 Plant extracts have been used for centuries to combat infectious human diseases in different

77 parts of the world. Such medicinal extracts are a mixture of several compounds, with many

78 extracts reported to have potent antimicrobial activities against wide range of drug resistant

79 microbes 5. Phenolics, terpenoids, alkaloids and lectins are some of the classes of compounds

80 present in plant extracts that exhibit strong antimicrobial activity. Antimicrobial activity has

81 been reported from various plant extracts such as Brillantaisia lamium, Crinum purpurascens,

82 Mangifera indica and Psidium guajava, against variety of pathogens including S. aureus,

83 Enterococcus faecalis, Candida tropicalis, Cryptococcus neoformans, and Salmonella

84 Paratyphi. Thus, plant-based materials form an abundant source for antimicrobials, that could

85 be economical, easy to process, and efficient against drug-resistant microbes. The Jackfruit is 86 one such plant product that fits this description. 
87 The fruit from the jack tree, botanically termed Artocarpus heterophyllus, belongs to the mulberry family, Moraceae. The fruit by itself is quite large, weighing approximately $4-10 \mathrm{~kg}$, commercially inexpensive, and widely consumed in south-east Asia and Africa 6. In addition to jackfruit's nutritional value, various components of the fruit possess a plethora of medicinal properties 7. The fruity arils are known to contain a cocktail of phytonutrients such as carotenoids 8 , isoflavones 9, saponins 10 and phenols 11 that are responsible for antioxidative and immunomodulatory properties 7. In addition, jackfruit leaf extract has been reported to possess antibacterial activities against Escherichia coli, Listeria monocytogenes, Salmonella typhimurium, Salmonella enterica, Bacillus cereus, Enterococcus faecalis, and S. aureus; 12. Heartwood has antibacterial activities against Bacillus subtilis, Streptococcus mutans, Streptococcus pyogenes, S. aureus and Staphylococcus epidermidis 13. In addition, extract derived from jackfruit seeds and shell powder have also been reported to demonstrate antibacterial activities against L. monocytogenes 14-16.

101 While parts of the ripe jackfruit including the pulpy aril and seeds are a culinary delicacy, the 102 rough, fibrous appendage called 'rag' that make up 10-20\% of the fruit are either discarded as non-edible fruit waste, or in some cultures, cooked and consumed. There are no known reports of rag's being used for medicinal purposes, although we have recently reported the use of the Jackfruit rag extract (JFRE) as a photo-sensitizer in solar cells 17. Since rags make up large 106 parts of the fruit and considering the existing lack of clarity towards their use for human benefit,

107 we set out to explore possible medicinal value of the rag, with specific focus on its potential as an alternative to antibiotics against human pathogenic bacteria. 


\section{Reagents}

111 Methanol, 2-Propanol and hydrochloric acid $(\mathrm{HCl})$ were purchased from Merck, India. 2, 2-

112 diphenyl-1-picrylhydrazyl hydrate (DPPH), 3-(4, 5, dimethylthiazol2-yl)-2, 5-

113 diphenyltetrazolium bromide (MTT), Glutaraldehyde and Triton-X 100 were purchased from

114 Sigma Aldrich, USA. Dulbecco's Modified Eagle's medium (DMEM) and RPMI-1640 were

115 purchased from Lonza, USA and fetal bovine serum (FBS) from Gibco, USA. Luria-Bertani

116 (LB) and De Man, Rogosa and Sharpe (MRS) medium (broth and agar) were purchased from

117 Himedia, India. Mouse dermal fibroblast (L929) cell line was obtained from National Center

118 for Cell Science (NCCS), Pune. All experiments were performed in triplicate unless mentioned

119 otherwise.

\section{Plant material and extract preparation}

121 Rags were separated from jackfruit (A. heterophyllus Lam, obtained from a marked tree located

122 in Shimoga district, Karnataka, India) and stored at $-20^{\circ} \mathrm{C}$ until further use. Air dried rags were

123 homogenized by grinding. Jackfruit rag extract (JFRE) was prepared by suspending the

124 powdered $\mathrm{rag}(10 \% \mathrm{w} / \mathrm{v})$ in $80 \%$ acidified $(1.2 \mathrm{~mol} \mathrm{l}-1 \mathrm{HCl})$ methanol and heated at $50^{\circ} \mathrm{C}$ for

$1255 \mathrm{~h}$, followed by addition of $100 \%$ methanol (1:2). Resulting solution was centrifuged $(10,000$

$126 \mathrm{~g}$, for $5 \mathrm{~min}$ at $4^{\circ} \mathrm{C}$ ), and the supernatant was further concentrated using solvent evaporation

127 techniques and lyophilized. The dried extract was then made up to a final concentration of 100

$128 \mathrm{mg}$ ml-1 in $100 \%$ methanol.

\section{Bacterial and fungal strains}

130 All the bacterial strains including Staphylococcus aureus (SA113), Mycobacterium smegmatis

131 (mc2155; ATCC700084), Escherichia coli (ATCC25922) and Pseudomonas aeruginosa 
(PA01; ATCC 15692), Shigella dysenteriae, Klebsiella pneumoniae, Lactobacillus fermentum, Proteus vulgaris, Salmonella Typhi and Salmonella Paratyphi A (Generously provided by Dr. cultured in Sabouraud dextrose (SD agar) at $37^{\circ} \mathrm{C}$.

\section{Morpho-physical characterization of the jackfruit rag and its extract}

138 Scanning electron microscopy: Surface morphology of rags was analyzed using a scanning electron microscope (JEOL, JSM-6490LA, Japan). Images were obtained after sputter coating

140 samples with gold and imaging at an accelerating voltage of $15 \mathrm{kV}$. Elemental analysis of

141 Jackfruit rag was performed using scanning electron microscope (SEM) equipped energy

142 dispersive X-ray (ULTRA55/GEMINI, Zeiss, Germany), after drop casting the rag powder on 143 silicon wafer.

144 UV-visible spectroscopy: Absorbance intensity of JFRE samples were measured from 400 to $145700 \mathrm{~nm}$ wavelength using a uv-visible spectrophotometer (Synergy H1, Biotek, USA).

146 Fourier transform infrared (FTIR) spectroscopy: was performed on JFRE (Perkin Elmer 147 spectrometer, L1860121, USA), by scanning samples from 4000-500 cm-1 for 32 consecutive 148 scans at room temperature.

149 Raman spectroscopy: was performed on JFRE using LabRAM HR UV-VIS-NIR Raman 150 microscope, Laser: 785 nm, Filter: D 0.6, Gratings: 600 IR, in the scanning range: 500-3000 $151 \mathrm{~cm}-1$.

152 Phytochemical tests on JFRE for detection of alkaloids, flavonoids, tannins, saponins and 153 cardiac glycosides was performed according to previously published standard procedures 18. 154 (Supplementary, materials and methods) 


\section{Gas chromatography-mass spectrometry}

156 GC-MS quantification of methanolic RAG extract was carried out based on a previously

157 published method 19, using Agilent 7890 GC system equipped with auto-sampler, HP-5ms

158 column and 7977A MSD mass detector (Agilent Technology). Briefly, $2 \mu 1$ of diluted (1:100)

159 sample (in pentane) was injected in splitless mode with Helium (He) as carrier gas. Inlet

160 temperature was kept at $250^{\circ} \mathrm{C}$ and the column flow was set for $1.5 \mathrm{ml} / \mathrm{min}$. The column oven

161 was programmed for initial hold of $2 \mathrm{~min}$ at $40^{\circ} \mathrm{C}$ followed by $150^{\circ} \mathrm{C}$ with the ramp of $5^{\circ} \mathrm{C}$

$162 \min -1$. After $3 \mathrm{~min}$ hold at $150^{\circ} \mathrm{C}$, the temperature was raised to $250^{\circ} \mathrm{C}$ with $\operatorname{ramp}$ of $5^{\circ} \mathrm{C}$ min-

163 and $3 \mathrm{~min}$ hold at $250^{\circ} \mathrm{C}$. Finally, the oven temperature was raised to $300^{\circ} \mathrm{C}$ with ramp of $10^{\circ}$

$164 \mathrm{C}$ min-1and 5 min final hold at $300^{\circ} \mathrm{C}$. MSD transfer line, MS Quad, and MS source temperature

165 were kept at $280^{\circ} \mathrm{C}, 150^{\circ} \mathrm{C}$ and $230^{\circ} \mathrm{C}$ respectively. Spectra acquired in scan mode were 166 processed analyzed and annotated using Mass hunter workstation software (Agilent

167 Technology) and NIST 11 library.

168 In vitro biocompatibility

169 Cell viability assay

170 L929 mouse fibroblasts were seeded in a 96-well plate at a density of 1x105 cells per well and

171 cultured under $5 \% \mathrm{CO}_{2}$, at $37^{\circ} \mathrm{C}$ for $24 \mathrm{~h}$ in DMEM media supplemented with $10 \% \mathrm{FBS}$ and

$1721 \%$ penicillin-streptomycin. After $24 \mathrm{~h}$, the culture media was replaced with fresh media

173 containing JFRE at concentrations of 0.1, 1, 10 and $100 \mathrm{mg}$ ml-1. Viability of the JFRE-exposed

174 L929 cells was determined using the MTT assay after $24 \mathrm{~h}$. Solubilized formazan absorbance

175 at $570 \mathrm{~nm}$ was measured using Biotek microplate reader (Synergy H1, Biotek, USA).

176 Hemolysis assay 
177 Female Sprague-Dawley rats weighing around 200-250 g were euthanized using carbon-

178 dioxide asphyxiation. Blood $(5 \mathrm{ml})$ was collected in $\mathrm{BD}$ vacutainer tubes and further diluted

179 with PBS (pH 7.4) in 1:10 ratio. Blood samples were centrifuged at $700 \mathrm{~g}$ for 5 min to separate 180 erythrocytes from plasma, followed by addition of $0.1,1,10$ and $100 \mathrm{mg}$ ml-1 of JFRE in equal 181 proportion. This mixture was incubated at $37^{\circ} \mathrm{C}$ for $1 \mathrm{~h}$, followed by centrifugation at $700 \mathrm{~g}$ for

$1825 \mathrm{~min}$. Peak absorbance values of the supernatant was measured at $540 \mathrm{~nm}$ (Synergy H1, 183 Biotek, USA). Triton-X $100(0.2 \%)$ treated erythrocyte suspension was used as a comparative 184 positive control, and percent hemolysis in each sample groups was calculated relative to the 185 positive control.

\section{Agar well disc diffusion assays}

187 Antimicrobial activity of JFRE was evaluated using standardized agar well-diffusion assay 20.

188 Various microbial strains were plated, and $5 \mathrm{~mm}$ wells were created within agar plates. The wells were filled with either, JRFE $(0.1,1,10$ and $100 \mathrm{mg} \mathrm{ml}-1)$, vehicle (80\% methanol), or $1 \%$ penicillin-streptomycin solution (used as positive control for antibacterial activity assays) or Amphotericin-B (20 mg ml-1) used as positive control for antifungal activity assays), and incubated at $37^{\circ} \mathrm{C}$ for $24-48 \mathrm{~h}$. Plates were imaged using Chemidoc ${ }^{\mathrm{TM}}$ Imager (Bio-Rad, USA), and zones of inhibition quantified using ImageJ software 21. Minimum inhibitory concentration

194 and minimum bactericidal concentration of JFRE against various bacterial strains were 195 determined using the standardized broth dilution method as reported previously 22.

\section{Fly experiments}

197 Adult male D. melanogaster flies (4-5 d old) were raised in flasks containing classic bananaagar media, maintained at $60 \%$ humidity, and at $28^{\circ} \mathrm{C}$. All feeding experiments were performed

199 by placing JFRE $(100 \mathrm{mg} \mathrm{ml-1})$ or bacterial solution soaked $(60 \mu \mathrm{l})$ circular filter paper discs on-top of banana-agar feed within each flask. $S$. dysenteriae cultured in $5 \mathrm{ml} \mathrm{LB}$ broth $(16 \mathrm{~h}$ at 
$20137^{\circ} \mathrm{C}$ ), were pelleted and resuspended in PBS and subsequently used to infect flies. Four-hour

202 pre-starved flies were allowed access to S. dysenteriae-infected feed for $24 \mathrm{~h}$. Flies in the 203 experimental group received JFRE feed, while the control groups received fresh banana agar.

204 Flies were observed for 21 days and the number of surviving flies was counted each day.

\section{Statistical analysis}

206 All data are shown as mean \pm standard deviation (SD). Difference in mean values among 207 various experimental groups were statistically tested using one-way ANOVA with post-hoc 208 Bonferroni multiple comparison test, unless mentioned otherwise. A ' $p$ ' value of $<0.05$ was 209 considered as statistically significant. 


\section{Physio-chemical characteristics of the jackfruit rag}

212 On gross examination, the JFRs appear as yellowish-white fibrous bands with a smooth and

213 shiny external surface, measuring approximately 5-6 cm in length, $0.5-0.7 \mathrm{~cm}$ in width, and 214 weighing about 0.1-0.5 g (Fig. 1a). SEM images of an individual rag exhibited a 'layered' 215 architecture (Fig. 1b), where dense 'honey-comb' patterned plant tissue (Fig. 1c) was 216 interspersed between layers of fibrous sheets. The methanol extract itself was deep red (Fig. 217 1a, inset) in color and exhibited an absorbance maximum at $540 \mathrm{~nm}$ (Fig. 1d). Lyophilization 218 of the extract yielded a dark-reddish powder. Using energy dispersive X-ray spectroscopy, it 219 was determined that the rag extract powder comprised primarily of carbon and oxygen (Table $220 \mathrm{~S} 1$ ), while other components such as $\mathrm{Na}, \mathrm{Cl}$ and $\mathrm{Si}$ that were observed in the elemental analysis were most likely due to washing techniques and background signal from the silicone sample222 loading wafer. Further chemical characterizations were performed using FTIR and Raman 223 spectroscopy. In FTIR (Fig. 2a), the absorption peak at $3375 \mathrm{~cm}-1$ likely corresponds to 224 hydroxyl groups $(-\mathrm{OH})$, and $1724 \mathrm{~cm}-1$ indicates carbonyl $(\mathrm{C}=\mathrm{O})$ corresponding to a carboxyl or ester group arising from pectin or fatty acid residue 23 . The observed, peaks at $1620 \mathrm{~cm}-1$ may be due to $\mathrm{C}=\mathrm{C}$ stretch, and a group of stretching frequencies in the range of $1074 \mathrm{~cm}-1-$ $1480 \mathrm{~cm}-1$ potentially due to the presence of $-\mathrm{CH}_{3}$ and/or $\mathrm{C}-\mathrm{O}$ group related to the flavonoids and hydroxyflavonoids 24. In addition, peaks at $2926 \mathrm{~cm}-1$ and $759 \mathrm{~cm}-1$, could be due to the asymmetric stretching of an aliphatic $\left(-\mathrm{CH}_{2}\right)$ group or bending mode of aromatic $(=\mathrm{CH})$ group. Similarly, the $1450-1590 \mathrm{~cm}-1$ bands observed in Raman spectroscopy (Fig. 2b) may be attributed to aliphatic bending vibration and/or aromatic stretching vibration. Additionally, the strong Raman band at $1235 \mathrm{~cm}-1$ may be due to the twisting or rocking vibration of $-\mathrm{CH}_{2}$ group

233 present in alicyclic or aliphatic compounds 25.

234 Gas chromatography mass spectrometry 
235 To further identify the constituent compounds, the methanolic rag extract was subjected to GC-

236 MS analysis. The spectral scan of JFRE annotated through Mass hunter workstation software

237 (Agilent Technology) and NIST 11 library revealed six major constituent peaks which were

238 identified as: furfural; pentanoic acid 4-oxo-methyl ester; levoglucosenone; 3-acetoxy-3-

239 hydroxypropionic acid, methyl ester; citric acid, trimethyl ester; and hexadecanoic acid, methyl

240 ester (Fig. 2c). The major contributing peaks calculated on the basis of peak area abundance

241 were pentanoic acid, 4-oxo-, methyl ester (53.44\%), 3-acetoxy-3-hydroxypropionic acid,

242 methyl ester (27.06 \%), and citric acid, trimethyl ester (8.91\%) (Table 1).

243

\section{Phytochemical assessment of JFRE}

245 JFRE was subjected to an array of phytochemical screening tests (Supplementary, materials 246 and methods) to determine the presence of common compounds that have been previously

247 recognized to impart medicinal properties in plant extracts 26 . Results from phytochemical 248 screening assays demonstrated the presence of polyphenolics, including anthocyanins, 249 coumarins, and flavonoids. In addition, JFRE tested positive for compounds belonging to 250 terpenoid, saponin and cardiac glycoside groups (Table 2).

In vitro biocompatibility testing of JFRE

253 To determine possible toxic effects, we examined the response of mouse fibroblast cell-line

254 and rat erythrocytes to an acute exposure of JFRE. Viability of cultured fibroblast cells exposed

255 to media containing $0.1,1$, and $10 \mathrm{mg} \mathrm{ml-1}$ of JFRE for $24 \mathrm{~h}$ was assessed using the MTT assay

256 by measuring formazan absorbance at $570 \mathrm{~nm}$. Interestingly, absorbance measurements from

257 cultures exposed to JFRE were quite similar to those obtained from JFRE-free naïve cells (Fig.

258 3a), suggesting that the JFRE extract does not affect cellular viability in mammalian cells, at 
the concentrations tested. MTT measurements in cultures exposed to higher concentrations of

JFRE (> $10 \mathrm{mg} \mathrm{ml-1)}$ resulted in unreliable absorbance signals, possibly due to extract induced

interference in the assay, and hence higher JFRE concentrations were not tested.

262 Similarly, blood collected from female Sprague-Dawley rats was processed to isolate 263 erythrocytes, followed by the addition of $0.1,1,10$ and $100 \mathrm{mg}$ ml-1 of JFRE. Lysis of erythrocytes was assessed by measuring absorbance at $540 \mathrm{~nm}$ of the supernatant separated from the JFRE-erythrocyte mixture. JFRE-induced hemolysis was calculated by normalizing the resulting absorbance value against a completely hemolyzed erythrocyte control. We found that JFRE, at higher concentration induced $28 \%$ hemolysis $(p<0.05$, in comparison to all other groups), while lower concentrations produced hemolysis that was no different than PBS treated controls (Fig. 3b). These results suggest that JFRE possess hemolytic properties at higher concentrations, and hence caution needs to be exercised for potential applications related to

271 intravenous use.

\section{Antibacterial property of JFRE}

274 Antimicrobial activity of JFRE was assessed against a wide range of bacterial strains using agar well-diffusion and broth dilution assays. Interestingly, JFRE-exposed culture plates of both Gram-positive and Gram-negative bacteria demonstrated distinct zone of inhibition (Fig.

277 4a), suggesting broad-spectrum antibacterial activity of JFREs. Further, MIC and MBC values

278 of JFRE against all bacteria tested were in the range of 5-10 and 10-20 mg ml-1 respectively 279 (Table 3).

280 Even though JFRE exhibited inhibition of laboratory bacterial strains (Fig. 4b), it is quite 281 important that similar activity be examined in clinically relevant strains. Hence, we tested 282 antibacterial activity of JFRE against strains of methicillin resistant S. aureus, E. coli, S. 283 Paratyphi A and S. Typhi (Fig. 4c) derived from patient samples. Zones of inhibition similar to 
those observed in the laboratory strains were noticed. Since JFRE inhibited bacteria, irrespective of their strain, source, or antibiotic resistance, it is likely that the mechanism of action is different from conventional antibiotics 26,27. Incidentally, JFRE did not appear to have antifungal effects against $C$. albicans (data not shown). Further, we imaged JFRE exposed cultures of $S$. aureus and $S$. dysenteriae using SEM. While vehicle treated bacteria exhibited symmetrical cells with regular borders and uniform morphology (Fig. 5a i, iii), JFRE treated bacteria appeared shrunken with irregular margins (Fig. 5a ii, iv). In addition, JFRE components appeared to have covered the bacterial cell surface, giving a matted appearance. Additionally, TEM images clearly showed the disintegration of bacterial surface, with formation of translucent intracellular clumped structures in JFRE treated S. aureus (Fig. 5b ii). These results suggest that JFRE could be producing its antimicrobial effects by direct activity on the outer bacterial cell wall or membrane.

296

\section{Antibacterial effect of JFRE in S. dysenteriae-infected flies}

298 To test the applicability of antibacterial property of JFRE in vivo, we challenged S. dysenteriae

299 fed flies with JFRE and measured D. melanogaster survival rate for a period of 3 weeks. $S$. 300 dysenteriae-fed flies exhibited a sharp drop (75\%) in survival rate, starting 3-4 days after the 301 infected feed (Fig. 6 iv). The survival rate continued to drop for the next 2 weeks and by the 302 end of 15 days, the survival rate was $35 \%$. No further reduction in survival rate was observed 303 after two weeks. In stark contrast, S. dysenteriae-infected flies that were fed with the JFRE 304 demonstrated a survival rate of $95 \%$ at the end of three weeks (Fig. 6 iii). These findings were 305 quite similar to survival rates observed in uninfected flies that were treated with JFRE or vehicle alone (Fig. 6 i, ii), suggesting that JFRE protects against $S$. dysenteriae induced death 
Discussion

309 In this study, we set out to explore possible antimicrobial properties of JFREs. There have been

310 several studies characterizing various components of the jackfruit 10 and exhaustive lists have

311 been compiled on their multiple uses 28 , to the best of our knowledge, we have not come across

312 previous reports that have specifically focused on the jackfruit rag.

314 Morpho-physically, the yellowish-white rag has an interesting internal architecture, with each

315 individual rag exhibiting an internal honey-combed pattern, along with a hydrophilic surface,

316 considerable mechanical strength (tensile strength of $0.89 \pm 0.4 \mathrm{MPa}$ ), and slow degradation in

317 water (Figure S1). While the actual function of the jackfruit rag is not entirely clear, based on

318 the structure and mechanical strength, it appears that it may be primarily used by the plant as a

319 supportive, packing material to protect the fleshy aril and seeds. During the process of extract 320 preparation, rag powder suspended in acidified methanol yielded deep red color, with an 321 absorption maximum peak at $540 \mathrm{~nm}$. This observation strongly suggested the presence of 322 anthocyanins 29, which was further confirmed using an array of biochemical screening tests.

323 Further, the chemical characterization techniques of FTIR and Raman spectroscopy also 324 suggested a mixture of carbon, oxygen and hydrogen containing compounds. Considering that 325 the jackfruit belongs to the mulberry family which are well known for their high polyphenolic 326 and anthocyanin content 30, it would appear that jackfruit rag components also share similar 327 characteristics. Incidentally, GC MS analysis revealed strong peaks indicating the presence of 328 carboxylic acids, such as pentanoic acid and hydroxypropionic acid, that have been previously 329 recognized to possess antibacterial properties 31-33. Antioxidative property of JFRE was found 330 to be moderate to low (data not shown) and was not further pursued. 
We found that JFRE produced inhibitory zones in bacterial cultures at concentration of around $100 \mathrm{mg} \mathrm{ml-1}$ (MIC 5-10 mg ml-1), while lower concentrations produced weak or no inhibitory zones in culture plates. While inhibitory zones were observed in both gram-positive and gramnegative laboratory strains, we were surprised to observe similar zones of inhibition in all the strains of clinically relevant cultures of $S$. aureus, E. coli, S. Typhi and $S$. Paratyphi A. This wide-ranging spectrum of antibacterial activity by JFRE against different bacterial strains, strongly points towards a possible target mechanism that could be common against all bacteria. SEM images clearly showed rag extract-induced blebbing of bacterial cells, along with aggregation, and change in shape, possibly due to membrane permeabilization. Previous

341 studies have shown that bacterial cells that are normally impermeable to FITC, a fluorescent

342 dye, become FITC-permeant 34 after exposure to alcoholic extracts of various plant extracts mainly due to membrane permeabilization, destabilization, and disruption of membrane potential, resulting in cell blebbing and leakage of cellular contents 27. In agreement with previous studies on other plant extracts 35 , our results also indicate that JFRE causes changes in bacterial cell morphology that eventually leads to cell death.

In view of these findings, we further tested the antimicrobial activity of JFREs in $S$. dysenteriae infected fly model. The protective effect of rag extract against S. dysenteriaeinduced death was quite apparent, with $95 \%$ of the flies surviving for more than 3 weeks. This effect was consistently observed in all the three batches of fly cultures tested at different times.

352 Considering that flies were pre-fed with $S$. dysenteriae-infected agar a day before rag-extract 353 treatment, the rag extract appears to have directly prevented fly gut infection by eliminating $S$. dysenteriae and protecting flies from $S$. dysenteriae enterotoxin induced death. Further studies are however needed to identify the exact mechanism of JFRE-induced gut protection and its role in disrupting $S$. dysenteriae pathogenesis. It is also important to note that crude extracts, 
357 such as the one used in this study will contain a mixture of various bioactive molecules acting

358 in cohesion to bring about a functional outcome, rather than a single active molecule exerting

359 its effect 36.

360

361 Conclusion

362 In conclusion, we have demonstrated that the rag of jackfruit, which is generally considered as 363 a non-edible fruit waste, has significant antibacterial activity. It is non-toxic when ingested and

364 could possibly have applications in treating or preventing various drug resistant bacterial 365 infections. 
Acknowledgments

368 We would like to acknowledge Dr. Anil Kumar, Department of Microbiology, AIMS, Kochi 369 for generously providing bacterial strains. Department of Biotechnology, India for the

370 Ramalingaswamy fellowship grant to Dr. Sahadev Shankarappa, and Department of Science 371 and Technology for M. Tech grant to Ms. Dhwani N V. Dr. Nilkamal Pramanik is in receipt of 372 the national postdoctoral fellowship and Dr. Siddharth Jhunjhunwala has received the 373 Ramanujan Fellowship, both from the Department of Science and Technology. Govt. of India.

374 We would like to thank Mr. Kiran K.S for providing biochemical standards, Dr. Sabitha M for 375 providing silica gel, Ms. Maneesha K. Suresh for data validation and technical help, Dr. 376 Shantikumar V. Nair for critical comments on this manuscript, and Dr. Shivanee Shah for her 377 valuable editorial support. Importantly, we would like to thank Mr. Adithya Shankar, 378 Aramanekeri, for sourcing the raw materials for this study.

\section{Conflict of Interest}

381 The authors declare no conflict of interest. 


\section{References}

3831 Cunha BA, Antibiotic side effects. Med Clin North Am, 85 (2001) 149.

3842 Pietsch J, Meakins JL, Complications of povidine-iodine absorption in topically treated burn patients. Lancet, 307 (1976) 280.

3 Pogue JM, Lee J, Marchaim D, Yee V, Zhao JJ, Chopra T, et al., Incidence of and risk factors for colistin- associated nephrotoxicity in a large academic health system. Clin Infect Dis, 53 (2011) 879.

389

4 Spapen HD, Doorn KJ Van, Diltoer M, Verbrugghe W, Jacobs R, Dobbeleir N, et al., Retrospective evaluation of possible renal toxicity associated with continuous infusion of vancomycin in critically ill patients. Ann Intensive Care, 1 (2011) 26.

3925 Ríos JL, Recio MC, Medicinal plants and antimicrobial activity. J Ethnopharmacol, $100(2005) 80$.

6 Gupta D, Mann S, Sood A, Gupta RK, Phytochemical, nutritional and antioxidant acitivity evaluation of seeds of jackfruit (Artocarpus heterophyllus L.). Int J Pharma Bio Sci, 2 (2011) 336.

Jagtap UB, Bapat VA, Artocarpus: A review of its traditional uses, phytochemistry and pharmacology. J Ethnopharmacol, 129 (2010) 142.

3998 Chandrika UG, Jansz ER, Warnasuriya ND, Analysis of carotenoids in ripe jackfruit 400 (Artocarpus heterophyllus) kernel and study of their bioconversion in rats. $J$ Sci Food Agric, 85 (2005) 186. activity of jackfruit (Artocarpus heterophyllus) extract. J Med Bioeng, 4 (2015) 318. 
40410 Swami SB, Thakor NJ, Haldankar PM, Kalse SB, Jackfruit and its many functional

405 components as related to human health : a review. Compr Rev Food Sci Food Saf, 11

406 (2012) 565 .

40711 Jagtap UB, Panaskar SN, Bapat VA, Evaluation of antioxidant capacity and phenol

408 content in jackfruit (Artocarpus heterophyllus Lam.) fruit pulp. Plant Foods Hum Nutr,

409 65 (2010) 99.

Loizzo MR, Tundis R, Chandrika UG, Abeysekera AM, Menichini F, Frega NG, Antioxidant and antibacterial activities on foodborne pathogens of Artocarpus heterophyllus Lam . (Moraceae) leaves extracts. J Food Sci, 75 (2010) M291.

41313 Septama AW, Panichayupakaranant P, Antibacterial assay-guided isolation of active 414 compounds from Artocarpus heterophyllus heartwoods. Pharm Biol, 53 (2015) 1608.

41514 Khan MR, Omoloso AD, Kihara M, Antibacterial activity of Artocarpus heterophyllus. $416 \quad$ Fitoterapia, 74 (2003) 501.

41715 Sharma A, Gupta P, Verma AK, Preliminary nutritional and biological potential of Artocarpus heterophyllus L . shell powder. J Food Sci Technol, 52 (2015) 1339.

41916 Septama AW, Xiao J, Panichayupakaranant P, A synergistic effect of artocarpanone from Artocarpus heterophyllus L . (Moraceae) on the antibacterial activity of selected antibiotics and cell membrane permeability. J Intercult Ethnopharmacol, 6 (2017) 186.

42217 Ashok A, Mathew SE, Shivaram SB, Shankarappa SA, Nair S V., Shanmugam M, Cost effective natural photo-sensitizer from upcycled jackfruit rags for dye sensitized 424 solar cells. J Sci Adv Mater Devices, 3 (2018) 213.

42518 Banu KS, Cathrine L, General techniques involved in phytochemical analysis. Int J 
Adv Res Chem Sci, 2 (2015) 25.

42719 Akhtar R, Shahzad A, Alginate encapsulation in Glycyrrhiza glabra L. with phyto428 chemical profiling of root extracts of in vitro converted plants using GC-MS analysis. Asian Pac J Trop Biomed, 7 (2017) 855.

430

Nair S V, Baranwal G, Chatterjee M, Sachu A, Vasudevan AK, Bose C, et al., Antimicrobial activity of plumbagin, a naturally occurring naphthoquinone from Plumbago rosea, against Staphylococcus aureus and Candida albicans. Int J Med Microbiol, 306 (2016) 237.

21 Eliceiri K, Schneider CA, Rasband WS, Eliceiri KW, NIH Image to ImageJ : 25 years of image analysis. Nat Methods, 9 (2012) 671. nanoparticles into the intracellular compartment of polymorphonuclear leukocytes. Int J Biol Macromol, 74 (2015) 36.

Begum R, Aziz MG, Uddin MB, Yusof YA, Characterization of jackfruit (Artocarpus heterophyllus) waste pectin as influenced by various extraction conditions. Agric Agric Sci Procedia, 2 (2014) 244.

24 Silva AJ, Silva JR, De Souza NC, Souto PCS, Membranes from latex with propolis for biomedical applications. Mater Lett, 116 (2014) 235.

44425 Baranska M, Roman M, Cz. Dobrowolski J, Schulz H, Baranski R, Recent advances in raman carotenoids, and polyacetylenes. Curr Anal Chem, 9 (2013) 108.

44626 Cowan MM, Plant products as antimicrobial agents. Clin Microbiol Rev, 12 (1999) 564. 
44827 Latha LY, Darah I, Kassim MJNM, Sasidharan S, Antibacterial activity and morphological changes of Pseudomonas aeruginosa cells after exposure to vernonia cinerea extract. Ultrastruct Pathol, 34 (2010) 219.

29 Harborne JB, Phytochemical methods : a guide to modern techniques of plant analysis.

Bae SH, Suh HJ, Antioxidant activities of five different mulberry cultivars in Korea.

31 Sebastianes FLS, Cabedo N, Aouad N El, Valente AMMP, Lacava PT, Azevedo JL, et compound from siegesbeckia glabrescens. Molecules, 17 (2012) 12469. exhibit antimicrobial activity for oral microorganisms. Arch Oral Biol, 56 (2011) 650. Front Microbiol, 6 (2015) 577. 

$12(2013) 20$.

47336 Rasoanaivo P, Wright CW, Willcox ML, Gilbert B, Whole plant extracts versus single compounds for the treatment of malaria: synergy and positive interactions. Malar J, 10

475 (2011) S4. 
476 Table 1. Major constituents present in methanolic RAG extract identified through GC-MS

477 analysis

478

\begin{tabular}{|c|c|c|c|c|c|}
\hline & RT & Compound name & $\begin{array}{c}\text { Molecular } \\
\text { Formula }\end{array}$ & $\begin{array}{c}\text { Molecular } \\
\text { Weight (g mol-1) }\end{array}$ & Peak area $\%$ \\
\hline 1 & 6.52 & Furfural & $\mathrm{C}_{5} \mathrm{H}_{4} \mathrm{O}_{2}$ & 96.021 & 1.33 \\
\hline 2 & 10.84 & $\begin{array}{l}\text { Pentanoic acid, 4- } \\
\text { oxo-, methyl ester }\end{array}$ & $\mathrm{C}_{6} \mathrm{H}_{10} \mathrm{O}_{3}$ & 130.063 & 53.44 \\
\hline 3 & 14.17 & Levoglucosenone & $\mathrm{C}_{6} \mathrm{H}_{6} \mathrm{O}_{3}$ & 126.032 & 2.20 \\
\hline 4 & 14.82 & $\begin{array}{l}\text { 3-Acetoxy-3- } \\
\text { hydroxypropionic } \\
\text { acid, methyl ester }\end{array}$ & $\mathrm{C}_{6} \mathrm{H}_{10} \mathrm{O}_{5}$ & 162.053 & 27.06 \\
\hline 5 & 23.66 & $\begin{array}{l}\text { Citric acid, } \\
\text { trimethyl ester }\end{array}$ & $\mathrm{C}_{9} \mathrm{H}_{14} \mathrm{O}_{7}$ & 234.074 & 8.91 \\
\hline 6 & 35.91 & $\begin{array}{l}\text { Hexadecanoic } \\
\text { acid, methyl ester }\end{array}$ & $\mathrm{C}_{17} \mathrm{H}_{34} \mathrm{O}_{2}$ & 270.256 & 0.47 \\
\hline
\end{tabular}


479 Table 2. Biochemical analysis of JFRE.

480

\begin{tabular}{|c|c|c|}
\hline Class of compounds & & Results \\
\hline \multirow[t]{5}{*}{ Poly-Phenols } & & +++ \\
\hline & Flavonoids & + \\
\hline & Coumarins & ++ \\
\hline & Anthocyanins & +++ \\
\hline & Tannins & - \\
\hline \multicolumn{2}{|l|}{ Terpenoids } & ++ \\
\hline \multicolumn{2}{|l|}{ Alkaloids } & - \\
\hline \multicolumn{2}{|l|}{ Proteins } & - \\
\hline \multicolumn{2}{|l|}{ Amino acids } & - \\
\hline \multicolumn{2}{|l|}{ Saponins } & + \\
\hline \multicolumn{2}{|l|}{ Gum and mucilages } & - \\
\hline \multicolumn{2}{|l|}{ Cardiotonic glycosides } & ++ \\
\hline \multirow[t]{2}{*}{ Carbohydrates } & & + \\
\hline & educing sugars & + \\
\hline
\end{tabular}

(-): Absence of chemical compound; (+): Presence of chemical compound

$(+)<(++)<(+++)$ : Based on intensity of characteristic color 
bioRxiv preprint doi: https://doi.org/10.1101/2020.03.09.983015; this version posted March 9, 2020. The copyright holder for this preprint (which was not certified by peer review) is the author/funder. All rights reserved. No reuse allowed without permission.

481 Table 3. Antimicrobial activity of JFRE against laboratory strains of bacteria.

482

\begin{tabular}{ccc}
\multicolumn{1}{c}{ Bacteria } & MIC & MBC \\
\multicolumn{1}{c}{ Gram positive } & $(\mathrm{mg}$ ml-1) $)$ \\
\hline Staphylococcus aureas & 5.0 & 10 \\
Lactobacillus fermentum & 7.5 & 15 \\
Mycobacterium smegmatis & 7.5 & 15 \\
\multicolumn{1}{c}{ Gram negative } & & 10 \\
Escherichia coli & 5.0 & 10 \\
Shigella dysenteriae & 5.0 & 10 \\
Pseudomonas aeruginosa & 5.0 & 20 \\
Klebsiella pneumoniae & 10.0 & 15 \\
Proteus vulgaris & 7.5 & 15 \\
Salmonella Paratyphi A & 7.5 & \\
\hline
\end{tabular}


Figure Legends

484

485 Fig. 1. Characterization of jackfruit rag and extract. (a) Representative image of a peeled 486 jackfruit exhibiting yellowish-white rags, and (inset) the deep-red methanolic rag extract. (b,

c) Representative cross-sectional SEM images of a freshly harvested jackfruit rag. (d) UVvisible absorption spectra of varying dilutions of JFRE.

489

490

Fig. 2. Spectroscopic analysis of jackfruit rag extract. (a) Fourier Transform Infrared (b)

Raman spectroscopic analyses and (c) gas chromatography and mass spectroscopic studies to determine chemical composition of JFRE.

493

Fig. 3. In vitro biocompatibility profile of the jackfruit rag extract. (a) Quantitative comparison of formazan absorbance values at $570 \mathrm{~nm}$ using the MTT assay from L929 cells exposed to varying concentration of JFRE for $24 \mathrm{~h}$. (b) Quantitative comparison of hemolysis in erythrocyte suspension exposed to varying concentrations of JFRE. Percent hemolysis was calculated from peak absorbance values at $540 \mathrm{~nm}$ normalized to Triton-X induced hemolysis.

Fig. 4. In vitro antibacterial activity of the jackfruit rag extract. (a) Representative images exhibiting clear bacterial growth inhibitory zones around agar wells containing JFRE (x) and an antibiotic (y) within well-plates that were cultured with laboratory strains of S. aureus, and E. coli. (b, c) Representative growth inhibitory zones from all laboratory and clinical bacterial

504 strains tested in the study.

505 
508 bacteria exhibited irregular margins and had a 'matted' appearance. (b) TEM imaging of (ii)

509 JFRE treated S. aureus showed loss of cell wall integrity (magnified segment from fig b, ii,

510 inset) and dense cytoplasmic granularity, that was absent in (i) vehicle treated controls.

511

512 Fig. 6. Survival of $S$. dysenteriae infected flies on JFRE treatment. Kaplan-Meier survival

513 curves of $S$. dysenteriae pre-fed flies that were either fed JFRE, or vehicle alone. The dark bar

514 on the x-axis (s) indicates the time duration of $S$. dysenteriae feed, while the lighter bar

515 indicates the duration of JFRE/vehicle feed. $n=20$ per group. $* \mathrm{p}<0.05$. 

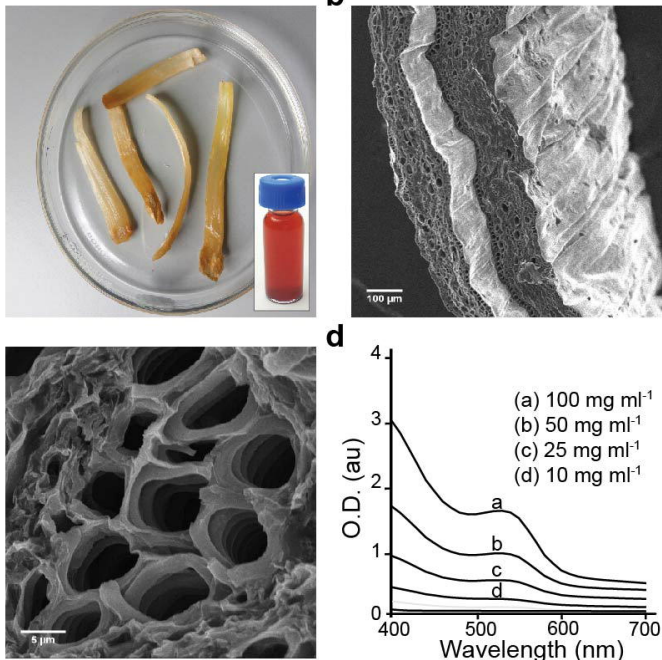

d

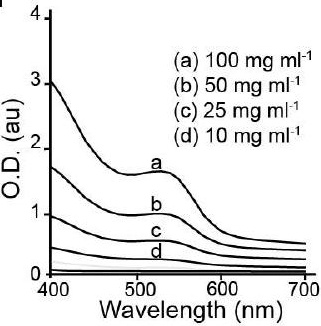



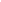


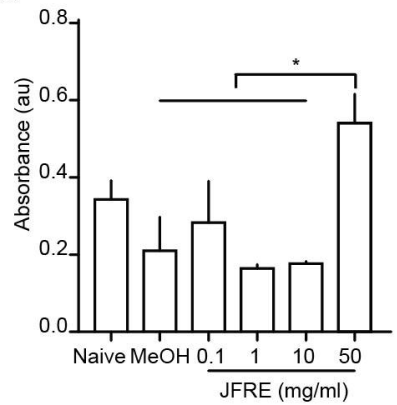

b

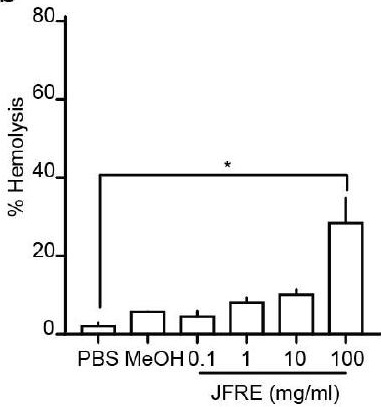


b

S. aureus

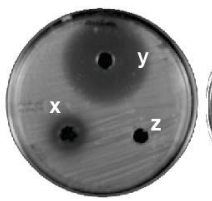

C

$\mathbf{x}$ - JFRE; y - Pen/Strep; $\mathbf{z}$ - Vehicle


S. aureas

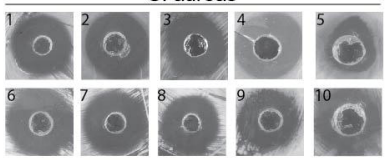

S. Paratyphi A

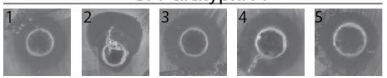

Gram positive
2

1 MRSA

$2 M$. smegmatis

\section{Gram negative}

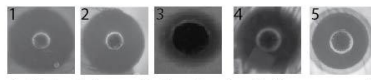

1S. Typhi A $3 P$. vulgaris 5 K. pneumoniae $2 P$. aeruginosa $4 \mathrm{~S}$. dysenteriae

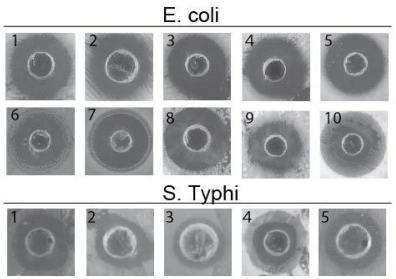




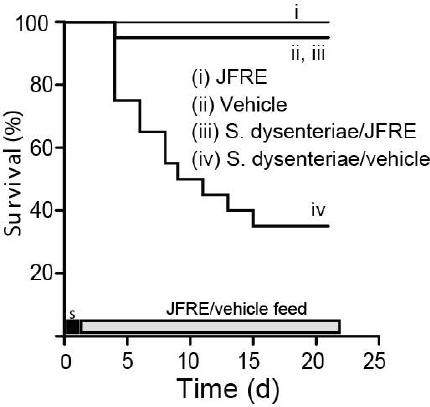

